\title{
A monitoring system of ankle rehabilitation for paralyzed patients using android aplication
}

\author{
Hanum Arrosida $^{\star 1}$, Asih Setiarini $^{2}$, Basuki Winarno $^{3}$, Albert Sudaryanto ${ }^{4}$ \\ Politeknik Negeri Madiun ${ }^{1,3,4}$ \\ Lembaga Ilmu Pengetahuan Indonesia ${ }^{2}$
}

\section{Article Info}

Keywords:

Bluetooth, Android, Arduino, Database, Ankle

Rehabilitation, Paralyzed Patients

\section{Article history:}

Received 9 August 2018

Revised 14 January 2019

Accepted 21 June 2019

Published 30 July 2019

\section{Cite:}

S Arrosida, H., Setiarini, A., Winarno, B., \& Sudaryanto, A. (2019). A Monitoring System of Ankle Rehabilitation For Paralyzed Patients Using Android Aplication. Kinetik: Game Technology, Information System, Computer Network, Computing, Electronics, and Control, 4(3).

doi:http://dx.doi.org/10.22219/kinetik.v4i3.674

${ }^{*}$ Corresponding author.

Hanum Arrosida

E-mail address:

hanumarrosida@pnm.ac.id

\begin{abstract}
A Monitoring system of ankle rehabilitation for paralyzed patients was successfully designed. The monitoring application on Android smartphone was made app inventor. This application uses bluetooth $\mathrm{HC}-05$ as a data transmission between the ankle therapy aids and smartphone Android. A MPX5050DP sensor is used to determine the muscle condition of the paraplegic to measure the muscle strength scale and control the motor dc speed of ankle rehabilitation hardware. The virtual keys on the application are five instructions of therapeutic movement such as, dorsiflexion $\left(20^{\circ}\right)$, plantarflection $\left(45^{\circ}\right)$, eversion $\left(10^{\circ}\right)$, inversion $\left(10^{\circ}\right)$ and patterned of movement. The access time to operate the ankle rehabilitation hardware is 0.8 seconds. This application includes an alarm and a database that can be used as a monitoring system. An alarm menu serves as a reminder for patients to take therapy and database to store data readings of sensors that converted into scale and muscle pressure. A MPX55050DP sensor output is displayed on smartphone application, stored in database and the therapy results are reserved to document format. The capacity of the database corresponds to the memory on the smartphone. Based on the measurement results, the ankle therapy application on android smartphone can control the system movement of ankle therapy aids and as a monitoring system of therapy results for paralyzed patients and make easily in analyzing the condition of leg muscle strength.
\end{abstract}

\section{Introduction}

The development of information and communication technology influences social interaction and lifestyle. One of the applications of information technology is in the field of health [1]. Nowdays, information applications that are integrated with health equipment have become researchers' interest. The existence of an Android smartphone give significant contribution to the development of information technology in making health monitoring applications [1], [2], [3], [4], [5], [6] which are portable and easy to use. [3] has made a health monitoring system intended for patients in remote areas. A very important android-based monitoring system such as heart rate, oxygen content, blood pressure has been carried out by [5]. This study focus on the Android monitoring system aplication that is used to operate the rehabilitation device.

Paralysis is the condition of a person who cannot move his body or part of his body. Physiotherapy is one of the methods used to restore a paralyzed patient to its original condition. Active rehabilitation training is more important than medical care because it can improve healing of damaged tissue, increase strength, stability, and muscle activity around treatment [7], [8], [9]. There has been conducted a research on the manufacture of human arm drive aids for paralyzed patients based on android voice command, which uses voice command commands from android as the driving command [6]. Android-based monitoring system application on this therapeutic tool serves to help the process of therapy for patients with ankle paralysis automatically using virtual key commands. To operate a therapeutic apparatus, use a smartphone that is connected to the HC-05 bluetooth module as a serial communication line to send data. The order will be converted into movement in a therapeutic apparatus to move the ankle of the paralyzed patient. This application is equipped with an alarm as a reminder of the implementation of therapy and a database that stores information on patient therapy. This application aims to monitor the development of leg muscle strength in patients with paralysis, safe to use and able to save costs in therapy.

\section{Research Method}

In previous studies, ankle therapy aids were still made manually. The study used MPX5050DP sensor as a system input. The sensor was placed in a cuff connected to the calf of a paralyzed patient, the aim was to measure the muscle strength of the sufferer. The muscle strength was converted into a muscle strength scale. The device consisted

Cite: S Arrosida, H., Setiarini, A., Winarno, B., \& Sudaryanto, A. (2019). A Monitoring System of Ankle Rehabilitation For Paralyzed Patients Using Android Aplication. Kinetik: Game Technology, Information System, Computer Network, Computing, Electronics, and Control, 4(3). doi:http://dx.doi.org/10.22219/kinetik.v4i3.674 
of five therapeutic movements, namely dorsiflexi, plantar flexi, eversion, inversion, and the movement of the four movements. In this study, an android-based application was made to monitor the results of therapy that had been carried out by patients. The result of therapy is the development of the strength of the calf muscle measured by the MPX5050DP sensor. There are three menus in the application, namely the operating menu, menu reminders or alarms and the monitoring menu.

\subsection{System Design Specifications}

The design of an ankle therapy monitoring system application system for Android-based paralytic patients consists of three parts, namely the input, process, and output section. Figure 1 shows block design diagram of an Android-based ankle therapy monitoring system.

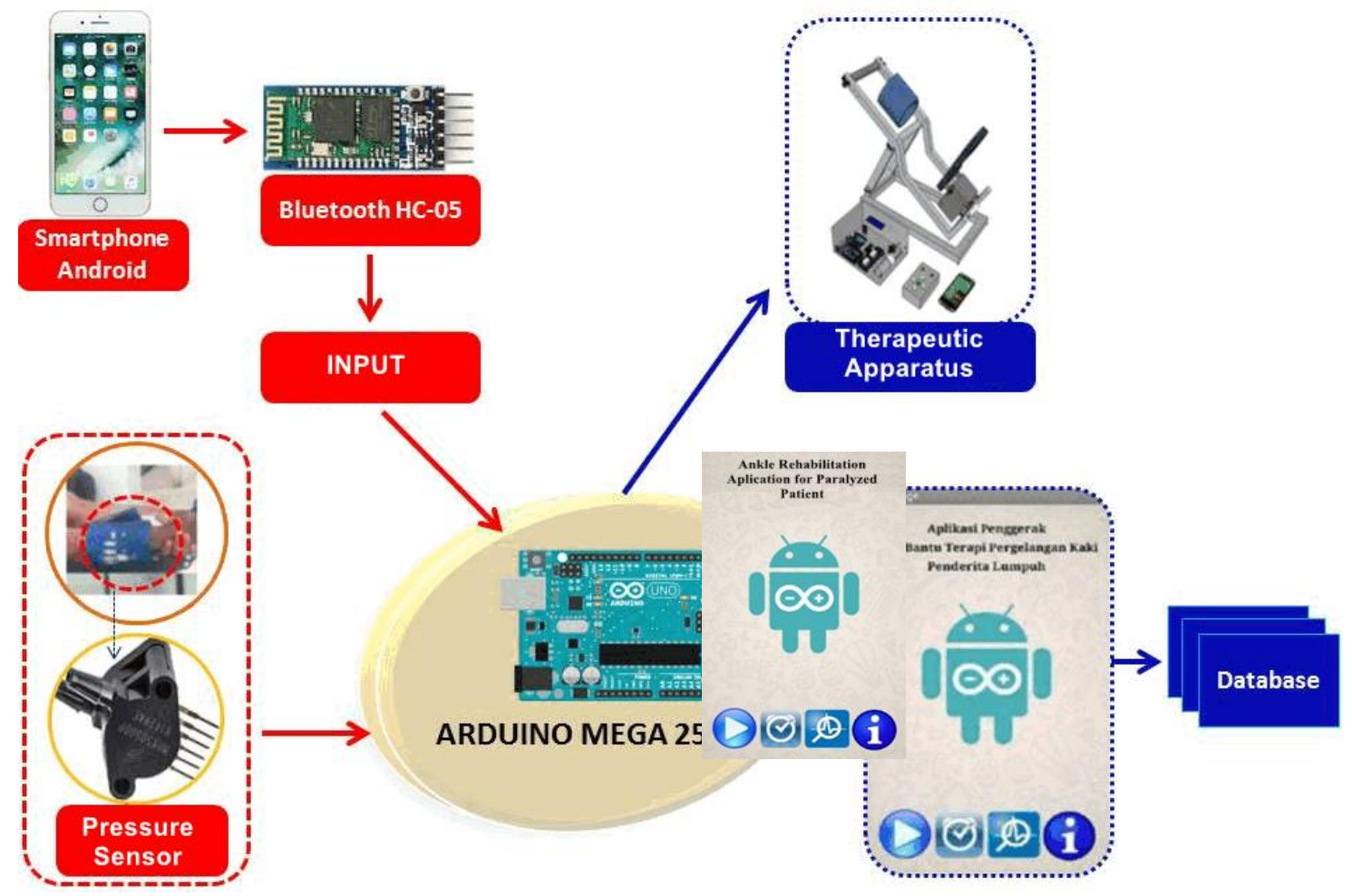

Figure 1. Block Diagram of Monitong System of Ankle Therapy

Based on Figure 1, MPX5050DP sensor output is input from the system that will be processed on Arduino. The MPX5050DP sensor is used to measure the strength of the calf muscles. For patients with paralysis of the legs, the calf muscles do not experience contractions so that the value of muscle strength is smaller compared to people with healthy legs. Where Bluetooth $\mathrm{HC}-05$ is a communication module used between smartphones and devices. The response from this android application is in the form of sending a text from a smartphone via bluetooth, while the response of the sensor is in the form of voltage. Arduino processes commands on the android application and sensor output to drive ankle therapy aids by translating text from bluetooth and the sensor readout voltage into a code. Arduino will match the code with the stored program. The therapeutic aids move according to the instructions selected and the motor speed is in accordance with the sensor reading. The results of the therapy can be displayed on the application installed on the Android smartphone and the results data is also stored directly in the database on the application that can be used to monitor patients.

\subsection{Calculation of Muscle Strength using MPX5050DP Sensor}

The MPX5050DP sensor on a paralyzed human ankle therapy aid is used to read the air pressure contained in the cuff. MPX5050DP sensor reading results is in the form of voltage that later be converted into pressure. The higher the voltage the sensor reads, the higher the pressure value will be generated. The air pressure is used to calculate the muscle strength of a paralyzed patient. Next, the incoming air pressure is converted into a muscle strength scale using a pressure formula [10]. The result of the conversion are converted by Bluetooth to the Android smartphone and used to determine the speed of movement of the ankle therapy device.

(c) 2019 The Authors. Published by Universitas Muhammadiyah Malang

This is an open access article under the CC BY SA license. (https://creativecommons.org/licenses/by-sa/4.0/) 


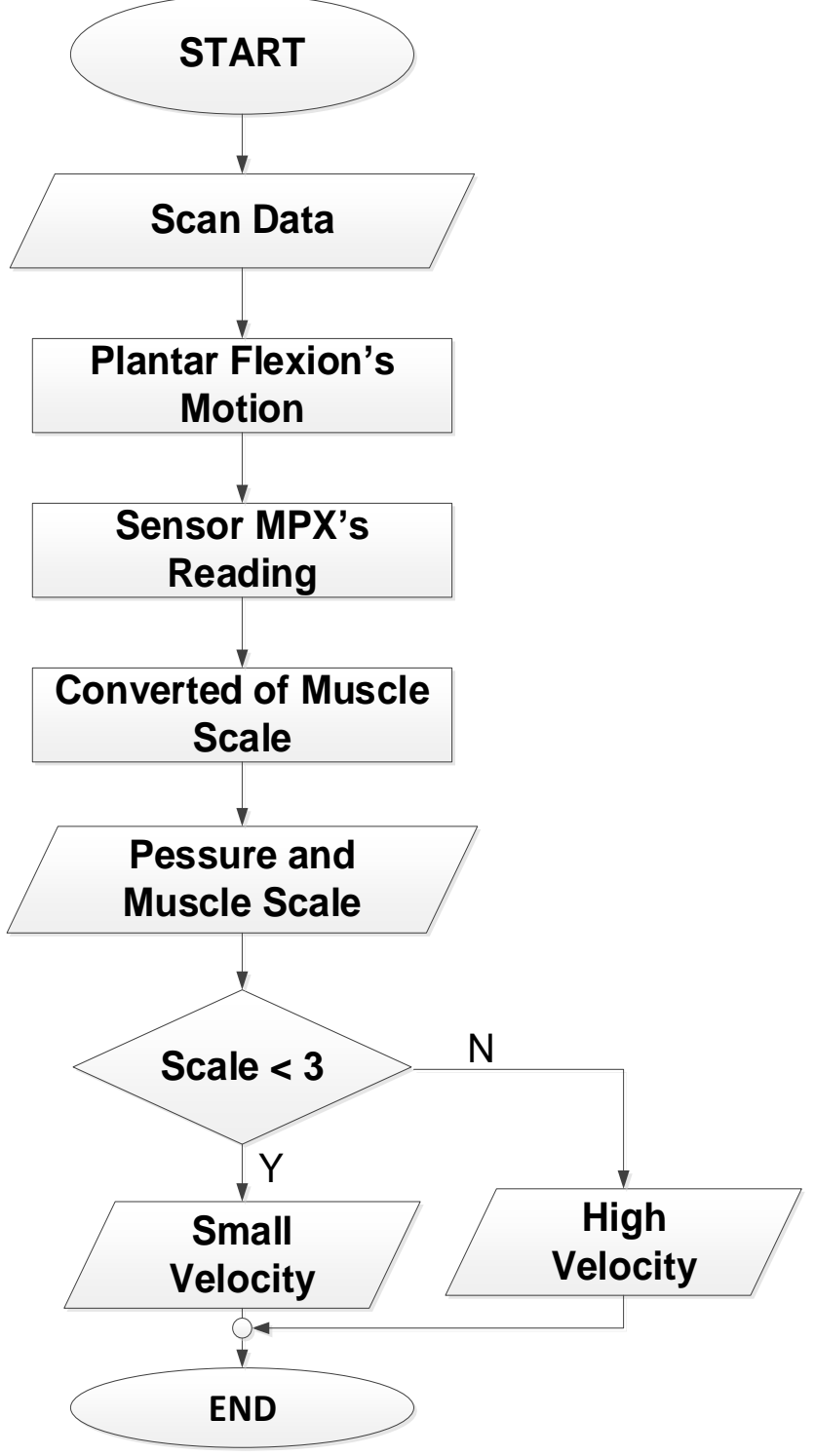

Figure 2. Flow Chart for Setting the Speed of the Therapeutic Device

Figure 2 states that, if the scale of the voltage conversion results from MPX5050DP sensor reading becomes less than 3 muscle pressure it means that the PWM value is 50 so that the speed of motion of the therapeutic instrument is slow. If the scale of the sufferer is more than 3, the PWM value is 100 and motion speed of the device is normal. Scale classification based on muscle strength is shown in Table 2.

\subsection{Bluetooth Connection}

Serial communication on ankle therapy aids for people with paralysis uses the HC-05 Bluetooth connection method with Bluetooth on an Android smartphone. This bluetooth circuit has 2 communication lines, the first communication is used as a data transmission line from the smartphone to the microcontroller while the second communication line is used as a data transmission path from the microcontroller to the smartphone. This application is working if the Bluetooth smartphone is connected with Bluetooth $\mathrm{HC}-05$. In this communication, the data is sent bits per bit, so the more data is sent, the longer it takes to get a response from the tool. The flow diagram of connecting a Bluetooth device to the smartphone and application is shown in Figure 3.

Figure 3 shows how to pair Bluetooth by entering Bluetooth code and connecting Bluetooth on Arduino with Android Android smartphone. If the entered code is not suitable then Bluetooth will not be connected and if the entered code matches, Bluetooth will be connected and the Android application can be used. Bluetooth devices that have been connected will automatically enter the Android application display when the Bluetooth icon is pressed.

Cite: S Arrosida, H., Setiarini, A., Winarno, B., \& Sudaryanto, A. (2019). A Monitoring System of Ankle Rehabilitation For Paralyzed Patients Using Android Aplication. Kinetik: Game Technology, Information System, Computer Network, Computing, Electronics, and Control, 4(3). doi:http://dx.doi.org/10.22219/kinetik.v4i3.674 


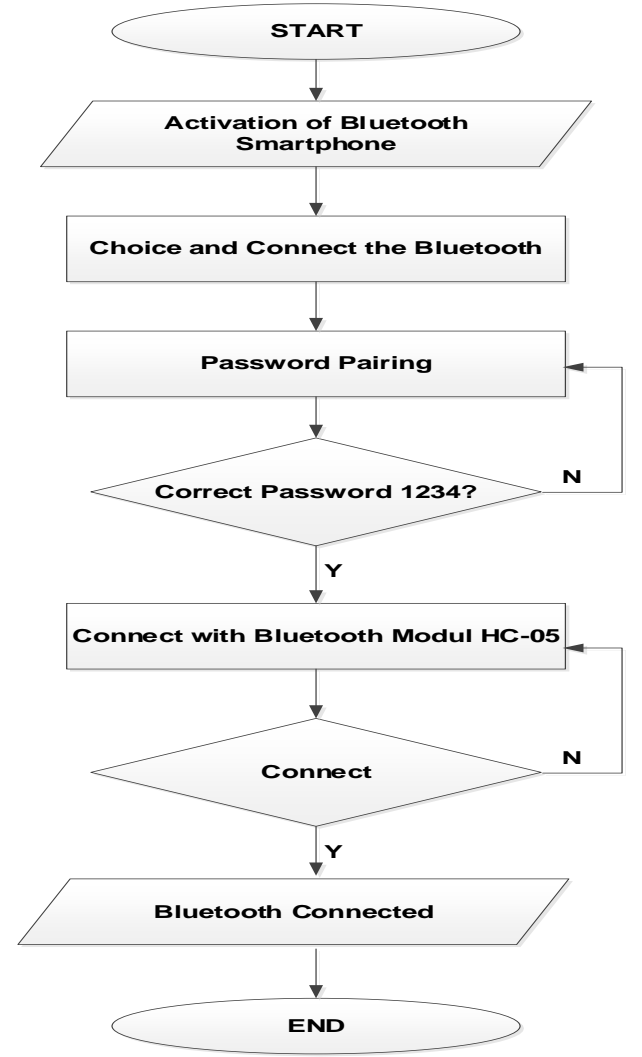

Figure 3. Bluetooth Communication Flow Diagram on the Application

\subsection{Operation Procedure}

The setting of the movement of ankle therapy devices uses a smartphone as input and Arduino Mega 2560 as a character data processor sent by Bluetooth, so that it can move the power window motor in accordance with the predetermined position. The movement of a therapeutic device is determined based on the character of the data received from the smartphone. Input from a smartphone is a virtual button. The work system of ankle therapy aids is based on virtual key commands. Figure 4 shows the flow diagram of the device motion system.

Figure 4 shows that, if the command button rises (dorsiflexion motion) presses, the motor will move at an angle of 200 , if the command button drops (the motion of the plant flexion is pressed the motor will move at an angle of 450 , if the right command button (eversion motion) is pressed the motor will move at an angle of 100 , if the command button up (inversion motion) is pressed the motor will move at an angle of 100 and if the command button pattern is pressed the motor will move in a pattern.

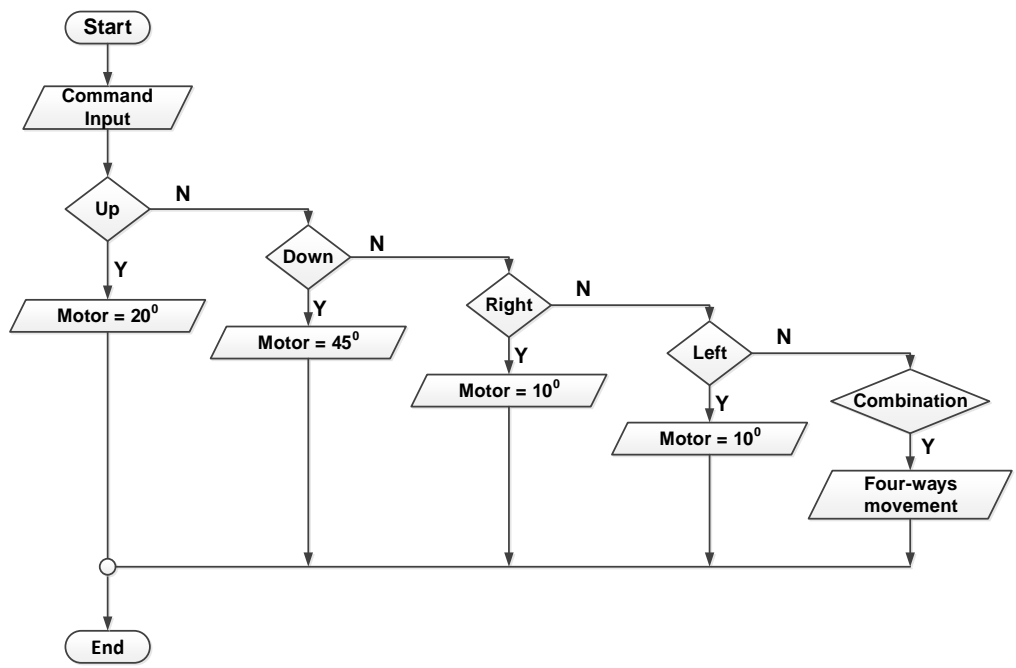

Figure 4. Device Motion System Diagram

(c) 2019 The Authors. Published by Universitas Muhammadiyah Malang

This is an open access article under the CC BY SA license. (https://creativecommons.org/licenses/by-sa/4.0/) 


\subsection{Therapeutic Apparatus Application}

This application is a medium for operating ankle therapy aids. This application was created on the appinventor.mit.edu page, a site to create applications for android smartphones. Figure 5 shows the application view, which is named FOOT THERAPY. This application is a medium to control the movement of ankle therapy aids. This application has four menus, namely:

1. Operation menu, initialized as a movement command from therapeutic aids.

2. Reminder menu, containing the alarm time setting for therapy implementation.

3. Monitoring menu, is a menu to see recap of therapy results.

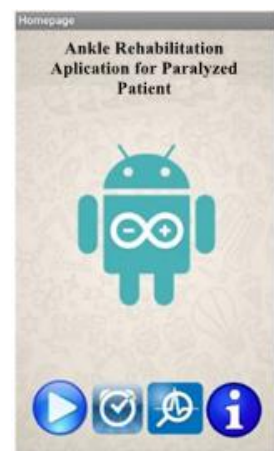

(a)

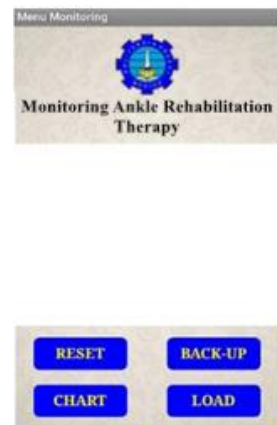

(d)

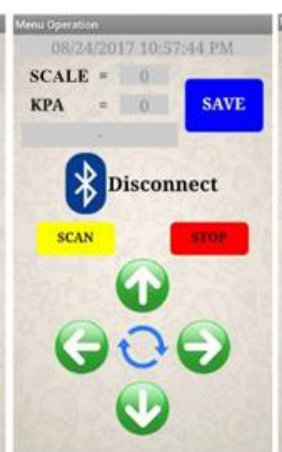

(b)

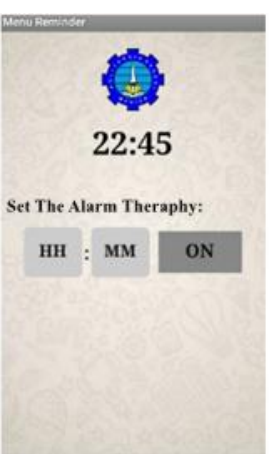

(c)

\section{Figure 5. Menu View on Android-Based Ankle Therapy Monitoring System Application}

Figure 5 (a) is the initial display that contains various menus from the application. Figure 5 (b) is a menu that contains the status of a Bluetooth connection, the therapy movement instructions, containing the scale and muscle strength in $\mathrm{kPa}$ and the save button is used to store data in the database. Figure 5 (c) is an alarm menu that is used as a reminder time for patients to do therapy. The Therapie are done twice a day. Figure 5 (d) is a monitoring menu of therapies that have been carried out. Muscle strength chart $(\mathrm{kPa})$ and scale shown in Figure $5(\mathrm{e})$, and Figure $5(\mathrm{f})$ is a menu of instructions for using tools and applications.

\subsection{Data Storage of Therapy Result}

The data from the MPX5050DP sensor reading is not only used to determine the speed of motion of the therapeutic device, but also to send to the smartphone to be displayed on the android application. The data sent are the result of the conversion of pressure in units of $\mathrm{kPa}$ and muscle scale which is the classification of the value of muscle pressure. Moreover, the date and time of therapy and comparison of the condition of the muscles of the paralyzed patient are also displayed. The therapeutic results data will be stored in the database contained in the application on Android. The data will be displayed in tables and graphs. Therapeutic results data can also be reserved in document format, so that therapeutic data can be displayed with or without the use of auxiliary device applications.

\section{Results and Discussion}

\subsection{Therapeutic Apparatus Application}

The calculation of muscle strength uses the MPX5050DP sensor by measuring the air pressure entering the cuffs attached to the calf of a paralyzed patient and formulated into a muscle strength scale. The formulation of the air pressure value that is used so that the voltage value of the sensor can be changed into $\mathrm{kPa}$ units is done by Equation 1 and Equation 2. 


$$
\begin{gathered}
V_{\text {out }}=((P \times 0.018)+0.04) \times 5 \\
P=\frac{\left(0.2 V_{\text {out }}-0.04\right)}{0.018}
\end{gathered}
$$

Formula description:

Vout $=$ Sensor Output

$\mathrm{P}=$ pressure

$5=$ Incoming Voltage

$0.018+0.04=$ Value of calibration of atmospheric pressure

Besides performing theoretical calculations, a pressure reading using a Manometer is also performed to determine the error of the MPX5050DP sensor, and obtained as shown in Table 1.

Table 1. Comparison of Theory Values and Voltage Values By Manometer Reading

\begin{tabular}{ccc}
\hline $\begin{array}{c}\text { Pressure } \\
\text { Theory }(\mathrm{kPa})\end{array}$ & $\begin{array}{c}\text { Pressure } \\
\text { Manometer }(\mathrm{kPa})\end{array}$ & Error \\
\hline 0.22 & 0 & $22 \%$ \\
7.01 & 7 & $1 \%$ \\
8 & 8 & $0 \%$ \\
9.01 & 9 & $1 \%$ \\
10.02 & 10 & $2 \%$ \\
11.01 & 11 & $1 \%$ \\
\hline
\end{tabular}

From Table 1, it can be seen that there are differences in pressure values based on calculations using formulas from the datasheet with the pressure value read by Manometer. There is an average error of $0.02 \mathrm{kPa}$. MPX5050DP sensor before air charging is $0.22 \mathrm{kPa}$ while the Manometer is $0 \mathrm{kPa}$. The difference in value is not an error but this value is the minimum value that can be detected by the MPX5050DP sensor.

From the experiments conducted on paralyzed patients and normal patients, the minimum and maximum values used as the set points to determine the muscle strength scale of paralyzed patients were $7 \mathrm{kPa}$ and $11.54 \mathrm{Kpa}$. From that result, the range of values will be classified into 5 scales where the value of the range will be divided equally.

From Table 2 it is known that if the pressure less than $8 \mathrm{kPa}$ it is classified as scale 1, if the scale between 8-9 $\mathrm{kPa}$ it is classified on scale 2, if the scale is between $9-10 \mathrm{kPa}$ it is classified as scale 3 , if the scale between $10-11 \mathrm{kPa}$ it is classified as scale 4 , and if a scale of more than $11 \mathrm{kPa}$ it is classified as a scale of 5 .

Table 2. Scale Classification Based on Muscle Stress Pressure

\begin{tabular}{cc}
\hline Pressure $(\mathrm{kPa})$ & Error \\
\hline$<8$ & 1 \\
$8-9$ & 2 \\
$9-10$ & 3 \\
$10-11$ & 4 \\
$>11$ & 5 \\
\hline
\end{tabular}

\subsection{Result}

Data transmission from the smartphone is done by pressing the virtual button found on the ankle therapy device drive application. In the driving application of ankle therapy aids there are seven virtual buttons that have different data characters, in which the character of the data will be converted into a movement on ankle therapy aids. The results of data reception can be seen in the Arduino IDE software serial monitor. Table 3 shows the sending of character data for the push button command on a smartphone.

\begin{tabular}{|c|c|c|c|}
\hline \multicolumn{2}{|c|}{ First Character } & \multicolumn{2}{|c|}{ Second Character } \\
\hline Transmit & Receive & Transmit & Receive \\
\hline Up & Ux & $\mathrm{u}$ & $\mathrm{u}$ \\
\hline Down & Doww & d & d \\
\hline Left & Ly: & I & I \\
\hline Right & Right & $r$ & $r$ \\
\hline
\end{tabular}

Table 3. Transmission Data From Smartphone

(c) 2019 The Authors. Published by Universitas Muhammadiyah Malang

This is an open access article under the CC BY SA license. (https://creativecommons.org/licenses/by-sa/4.0/) 


\begin{tabular}{cccc} 
Rotation & Rotation & $\mathrm{t}$ & $\mathrm{t}$ \\
Scan & $\mathrm{s}-X \mathrm{u}$ & $\mathrm{s}$ & $\mathrm{s}$ \\
Stop & Stop & $\mathrm{b}$ & $\mathrm{b}$ \\
Reset & Resez & $\mathrm{B}$ & $\mathrm{B}$ \\
\hline
\end{tabular}

Based on Table 3, it is known that the more characters sent, there are characters that are not delivered. The Data that do not match between data sent and data received will not produce any movement from ankle therapy aids. In addition, the more characters that are sent, the more time is needed for the device to respond to commands from an Android smartphone. The Data transmission time is shown in Table 4.

Table 4. Time of Data Transmission

\begin{tabular}{cccc}
\hline \multicolumn{2}{c}{ First Data } & \multicolumn{2}{c}{ Second Data } \\
\hline Character & Time (s) & Character & Time (s) \\
\hline Up & 1.92 & $\mathrm{u}$ & 0.8 \\
Down & 1.83 & $\mathrm{~d}$ & 0.6 \\
Left & 1.82 & $\mathrm{I}$ & 0.5 \\
Right & 1.84 & $\mathrm{r}$ & 0.7 \\
Rotation & 1.88 & $\mathrm{t}$ & 0.7 \\
Scan & 1.78 & $\mathrm{~s}$ & 0.8 \\
Stop & 1.61 & $\mathrm{~b}$ & 0.8 \\
Reset & 1.62 & $\mathrm{~B}$ & 0.8 \\
\hline
\end{tabular}

The second communication path from the Arduino microcontroller to the Android smartphone is used for sending the scale value of muscle strength and the value of muscle pressure by the Arduino Mega 2560 microcontroller which is the result of the MPX505DP sensor reading for display on an Android smartphone. The comparison of the value of muscle strength in smartphones and android is shown in Table 5.

Table 5. Comparison of Muscle Value on Smartphone and Android
\begin{tabular}{cccc}
\multicolumn{2}{c}{ Arduino Mega 2560} & \multicolumn{3}{c}{ Android } \\
\hline Value & Scale & Value & Scale \\
\hline 7.61 & 1 & 7.61 & 1 \\
8.64 & 2 & 8.64 & 2 \\
9.51 & 3 & 9.51 & 3 \\
10.59 & 4 & 10.59 & 4 \\
11.41 & 5 & 11.41 & 5 \\
\hline
\end{tabular}

Table 5 shows that the pressure value and scale of muscle strength sent by Arduino are the same as the values displayed on the Android application. From testing sending and receiving data via Bluetooth, it can be concluded that serial communication between smartphones and Arduino runs well. Bluetooth can receive and transmit data from both devices.

Testing of the use of android on ankle therapy aids was carried out on two normal people and two paralyzed patients. Tests are carried out in the morning and evening for four consecutive days. Testing of monitoring system applications in normal people aged 21 and 20 years is shown in Figure 6. Test results in the form of pressure data and muscle strength scale are shown in Table 6.
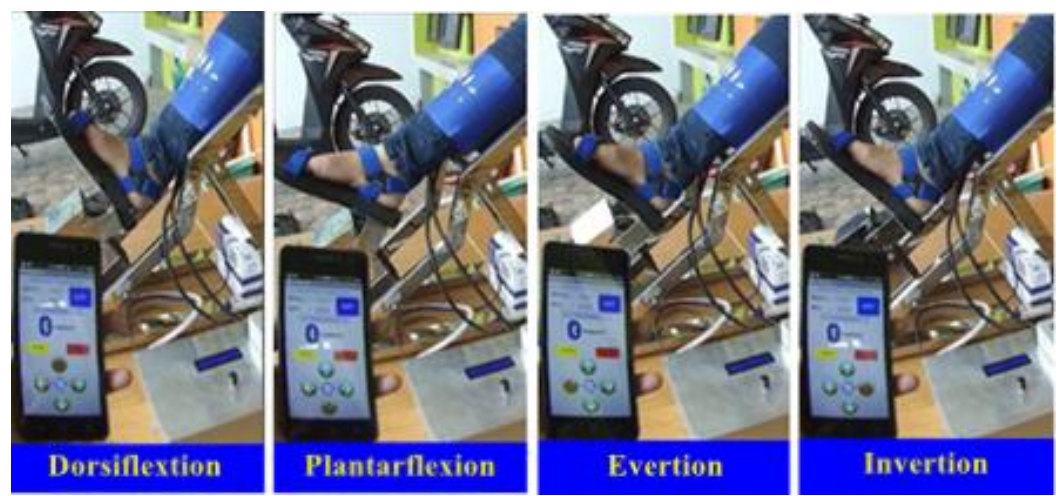

Figure 6. Testing Ankle Therapy Aids in Normal People

Cite: S Arrosida, H., Setiarini, A., Winarno, B., \& Sudaryanto, A. (2019). A Monitoring System of Ankle Rehabilitation For Paralyzed Patients Using Android Aplication. Kinetik: Game Technology, Information System, Computer Network, Computing, Electronics, and Control, 4(3). doi:http://dx.doi.org/10.22219/kinetik.v4i3.674 
Table 6. Pressure Data and Scale of Normal People

\begin{tabular}{ccccc}
\hline \multirow{2}{*}{\begin{tabular}{c} 
Number $\begin{array}{c}\text { of } \\
\text { theraphy }\end{array}$ \\
\cline { 2 - 5 }
\end{tabular}} & $\begin{array}{c}\text { Pressure } \\
(\mathrm{kPa})\end{array}$ & Scale & $\begin{array}{c}\text { Pressure } \\
(\mathrm{kPa})\end{array}$ & Scale \\
\hline 1 & 11.15 & 5 & 13.37 & 5 \\
2 & 11.17 & 5 & 13.35 & 5 \\
3 & 11.14 & 5 & 13.36 & 5 \\
4 & 11.15 & 5 & 13.37 & 5 \\
5 & 11.13 & 5 & 13.38 & 5 \\
6 & 11.16 & 5 & 13.36 & 5 \\
7 & 11.17 & 5 & 13.37 & 5 \\
8 & 11.14 & 5 & 13.37 & 5 \\
\hline
\end{tabular}

In the driving application of ankle therapy aids, these data are stored in a database and displayed in tables and graphs to facilitate users in monitoring the development of the condition of the muscles of paralysis sufferers. Therapeutic results data can also be backed up in document format so that the patient's therapeutic data is not lost and can be monitored with or without an ankle therapy device auxiliary application. From the tests carried out to normal people, it was known that the value of up and down muscle strength pressure tends to be stable with fixed scale value. The value of muscle pressure in each person of different sex also affects the size of the muscle pressure given. Figure 7 shows the display of the monitoring menu in people whose feet are in good health. Whereas Figure 8 is a display of ankle therapy monitoring menu in the form of a pressure chart and muscle strength scale.

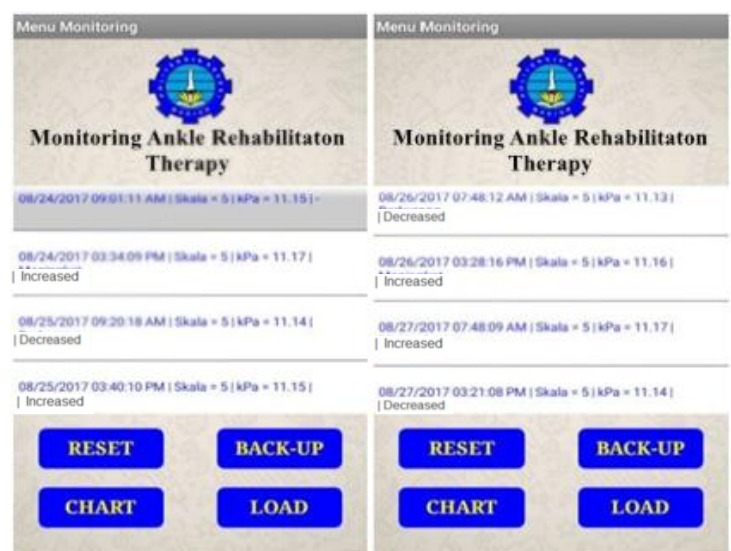

Figure 7. Display Ankle Therapy Monitoring Menu in Healthy People

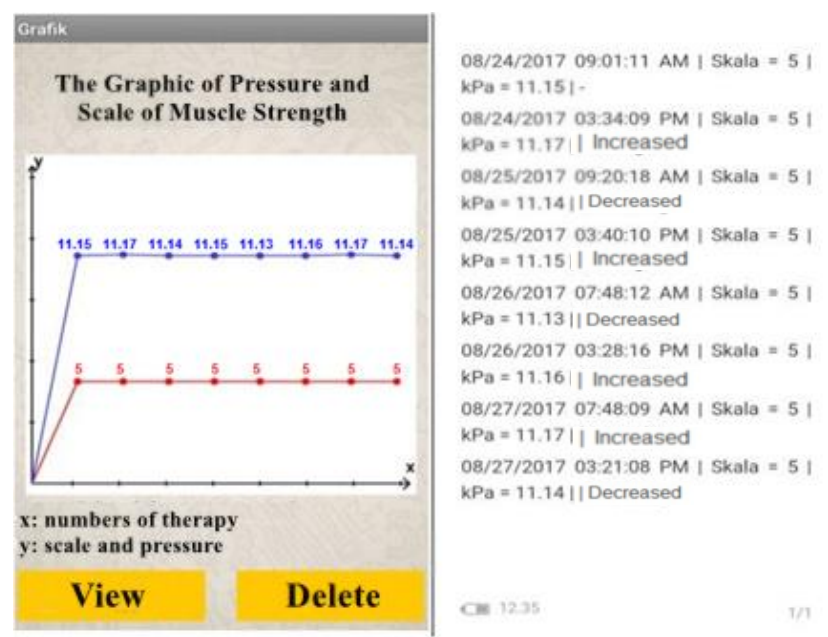

Figure 8. Display of Ankle Therapy Monitoring Menu in The Form of Pressure Charts and Muscle Strength Scale

Based on the graph in Figure 7 and Figure 8 data in the monitoring menu in the form of text and graphics have the same value, while the test for a paralyzed person is shown in Figure 9. Participants 3 and 4 are temporary paralytic

(C) 2019 The Authors. Published by Universitas Muhammadiyah Malang

This is an open access article under the CC BY SA license. (https://creativecommons.org/licenses/by-sa/4.0/) 
patients post stroke with age 47 and 51 years. The results of the test for paralyzed patients are shown in Table 7. Figure 10 and Figure 11 shows the monitoring menu of the results of therapy of paralyzed patients in the form of data and graphs in a row.
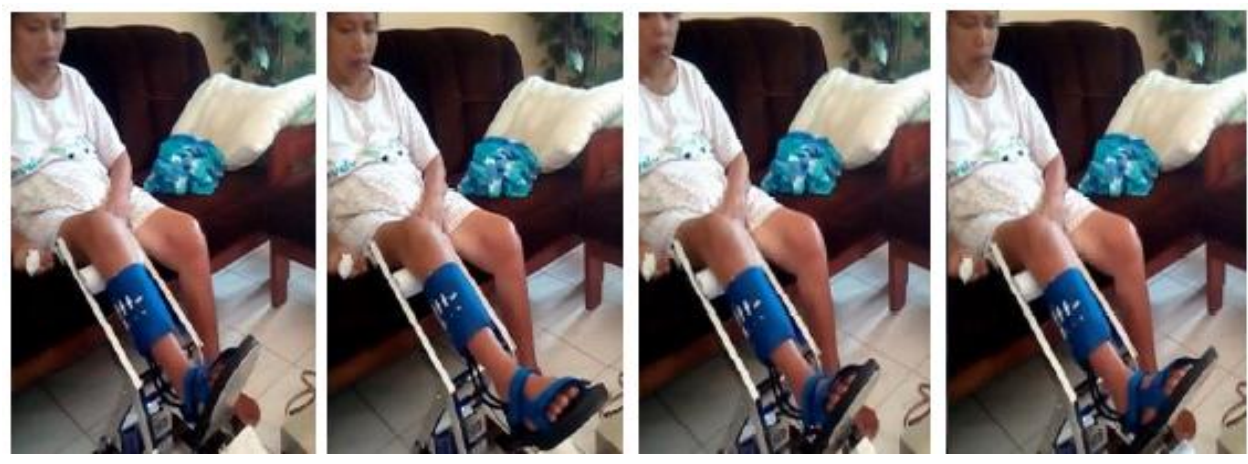

Figure 9. Testing Ankle Therapy Aids in People with Paralysis

\begin{tabular}{|c|c|c|c|c|}
\hline \multirow{2}{*}{$\begin{array}{l}\text { Number } \\
\text { of } \\
\text { theraphy }\end{array}$} & \multicolumn{2}{|c|}{ Third Participant } & \multicolumn{2}{|c|}{ Fourth Participant } \\
\hline & $\begin{array}{c}\text { Pressure } \\
(\mathrm{kPa})\end{array}$ & Scale & $\begin{array}{c}\text { Pressure } \\
(\mathrm{kPa})\end{array}$ & Scale \\
\hline 1 & 9.45 & 3 & 8.60 & 2 \\
\hline 2 & 9.48 & 3 & 8.60 & 2 \\
\hline 3 & 9.44 & 3 & 8.63 & 2 \\
\hline 4 & 9.53 & 3 & 8.68 & 2 \\
\hline 5 & 9.55 & 3 & 8.69 & 2 \\
\hline 6 & 9.59 & 3 & 8,72 & 2 \\
\hline 7 & 9.60 & 3 & 8.71 & 2 \\
\hline 8 & 9.64 & 3 & 8.72 & 2 \\
\hline
\end{tabular}

Based on the results of the graph on the android-base human ankle of paralytic patients monitoring menu, have been successfully tested on people whose leg conditions are healthy and those with paralysis. Users are easily able to read the results of the therapy that has been done. In normal people, the value of muscle pressure tends to be stable because the muscles in normal people can function perfectly, while the movement of ankle therapy aids in people with paralysis results in an increase in results because the movement of ankle therapy aids triggers the muscles in the paralyzed patient to actively move back.

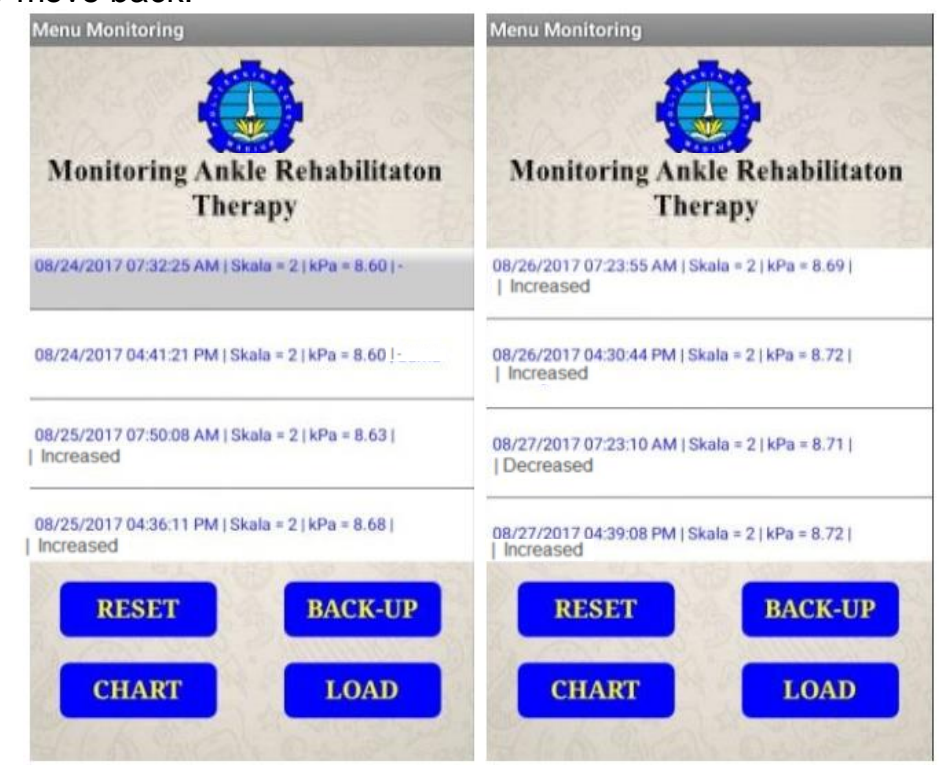

Figure 10. Display of Ankle Therapy Monitoring Menu in Paralyzed Patients 

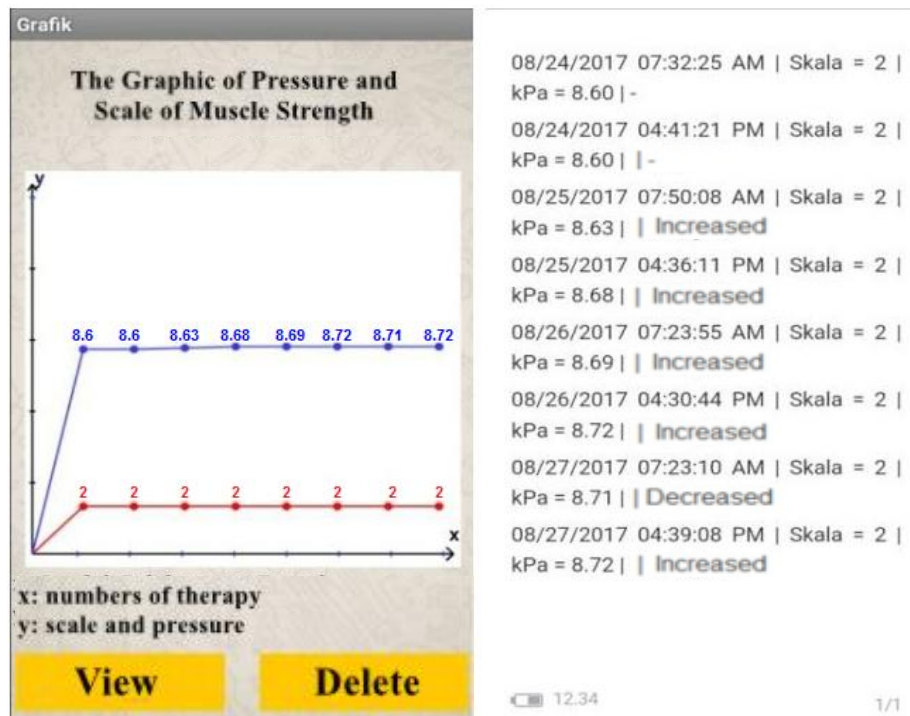

View

Delete

Figure 11. Display Ankle Therapy Monitoring Menu in The Form of A Graph of Pressure and Muscle Strength Scale in Paralyzed Patients

\section{Conclusion}

The monitoring system application of ankle therapy results on Android-based paralytic patients has been successfully made. This application can work well for all therapeutic movements and each menu has also been tested. This application is able to connect the hardware of the appliance to the Android smartphone that has been installed with a foot therapy application using Bluetooth communication. The results read by the foot therapy application are the same as the manual readings listed on the tool. The monitoring menu in the form of text can be presented in graphical form that can facilitate users or therapists who use this ankle therapy aid. Therapeutic results data can be stored and displayed in tables, graphics and text. This data storage aims to make it easier for users to monitor the condition of the muscles of a paralyzed patient. This application can be used as a driving medium for ankle therapy aids, this application can also be used as a medium to monitor the development of leg muscles in paralyzed patients.

\section{Acknowledgement}

The authors thanks to Kemenristekdikti on Penelitian Dosen Pemula program for funds the implementation of this research. The authors also thanks to the Berfian Heppy Loradion and Frida Endah as students of the Politeknik Negeri Madiun, Computer Control Engineering for their assistance in retrieving participant data.

\section{References}

[1] K. Mathan Kumar and R.S. Venkatesan, "A Design Approach to Smart Health Monitoring Using Android Mobile Devices," Proc. ICACCCT, Pp. 1740 - 1744, May 2014. https://doi.org/10.1109/ICACCCT.2014.7019406

[2] Isabel de la Torre-Díez, Bruno Olivar Trinchet, Joel J.P.C. Rodrigues, Miguel López-Coronado, "Security analysis of a mHealth app in Android: Problems and solutions," IEEE 19th International Conference on e-Health Networking. Applications and Services (Healthcom), Pp. 1-6, October, 2017. https://doi.org/10.1109/HealthCom.2017.8210757

[3] N. Dorosh, H. Kuchmiy, O. Boyko, O. Dorosh, O. Stepanjuk, and N. Maritz, "Development the Software Applications for mobile Medical Systems Based on OS Android," 13th International Conference on Modern Problems of Radio Engineering, Telecommunications and Computer Science (TCSET), Pp. 808-810, February, 2016. https://doi.org/10.1109/TCSET.2016.7452190

[4] Suresh Sankaranarayanan and Au Thien Wan, "ABASH - Android Based Smart Home Monitoring using Wireless Sensors," IEEE Conference on Clean Energy and Technology (CEAT), Pp. 494-499, November, 2013. https://doi.org/10.1109/CEAT.2013.6775683

[5] Matthias Wagner, Benjamin Kuch, Carlos Cabrera, Peter Enoksson, Arne Sieber, "Android Based Body Area Network for the Evaluation of Medical Parameters," Proceedings of the 10th International Workshop on Intelligent Solutions in Embedded Systems, Pp. 33 - 38, July 2012.

[6] Yupeng Ren, Yi-Ning Wu, Chung-Yong Yang, Tao Xu, Richard L. Harvey, and Li-Qun Zhang, "Developing a Wearable Ankle Rehabilitation Robotic Device for in-bed Acute Stroke Rehabilitation," in IEEE Trans Neuro Syst Rehab Eng, Vol. 25, Pp. 1-8, June 2017. https://doi.org/10.1109/TNSRE.2016.2584003

[7] A Setiarini, HNK Ningrum, M Luqman, RY Okananda, "Rancang Bangun Alat Bantu Physiotherapy Penggerak Lengan Manusia Untuk Penderita Lumpuh Parsial Sementara Berbasis Voice Command Android," Jurnal TELKA-Telekomunikasi, Elektronika, Komputasi dan Kontrol, Vol.3 No.2, Pp. 112-124, November, 2017. https://doi.org/10.15575/telka.v3n2.112-124

[8] Claire L, Brockett, Graham J, Chapman, "Basic Science: Biomechanic of the Ankle," Orthopaedics and Trauma, Vol.30, Issue 3, Pp. 232-238, June 2016. https://doi.org/10.1016/j.mporth.2016.04.015

[9] Yi-Ning Wu, Yupeng Ren, Miriam Hwang, Deborah J. Gaebler-Spira, Li-Qun Zhang, "Efficacy of Robotic Rehabilitation of Ankle Impairments in Children with Cerebral Palsy," in Proc. International Conference of the IEEE EMBS, Pp.4481-4484, August 2010. https://doi.org/10.1109/IEMBS.2010.5626043

[10] "Datasheet MPX5050 and MPX5050G Series," Freescale Semiconductor

(c) 2019 The Authors. Published by Universitas Muhammadiyah Malang

This is an open access article under the CC BY SA license. (https://creativecommons.org/licenses/by-sa/4.0/) 